\title{
Study on Communication Advantage and Creation Strategy of Suspense Advertisement
}

\author{
Mi Yang \\ School of Art \\ Binzhou University \\ Binzhou, China 256600
}

\begin{abstract}
In the information explosion time, modern people's life is filled with all kinds of advertising information all the time. As a result, modern people have generated disgust and aversion toward advertisement gradually. Enterprises must find a new advertising creative path to smoothly transfer business information to the target consumers. At the moment, suspense skills emerge in response to the needs of times. The application of suspense skills in advertisement can make the advertisement appear to be lively, rending the advertisements with new connotation and vitality, enabling the audience to receive information conveyed by advertisements with a good mood, which has enhanced people's acceptance and attention of advertising information. Suspense can set be set from the aspects of advertisements' text, graphics, images and stories skillfully, rendering the unique appeal, reflecting the unique creativity, so as to break through the convention, deepen the theme, strengthen brand personality, thus to obtain a good effect in the fierce market competition.
\end{abstract}

\section{Keywords -suspense; advertisement; creativity; strategy}

\section{INTRODUCTION}

In recent years, commercial advertising has reached the point of all-pervasive in people's daily life. People have higher requirements of commercial advertising, as the pure visual advertising has a lot of disadvantages, and the mediocre advertising cannot arouse people's interest, which has promoted the advertisers to constantly explore and seek new path in terms of advertising creative, expression skills and technique. As a saying goes "good article seems like the mountain which is bumpiness", as for advertising, "bumpiness" refers to rich changes. Setting up suspense is a kind of effective advertising creative. If audiences are attracted by advertising, then it can be said that the advertisement has already had half success. In the process of advertising creative, using suspense language with innovation, breaking the plain framework, and constructing the information to be conveyed by the merchants with ingenuity, may make the advertisements changeful with the effect of break a new path, so as to attract people to pay attention to the products, and produce purchase desire, realizing merchants' goal of spreading commercial information.

\section{COMMUNICATION ADVANTAGE OF SUSPENSE ADVERTISEMENT}

\section{A. Connotation of Suspense Advertisement}

Curiosity is a potential instinct of people, which is a feeling of can't help carrying on after adjusting people's ordinary mood, reducing peoples' inner depression and anxiety, and it is beneficial to health. Suspense advertising has just catered to people's curiosity psychology, enabling people to obtain the spiritual pleasure and spiritual enjoyment through the visual effect created deliberately by curiosity and suspense, and to accept relevant information conveyed by the merchants with delightful mood, but not to be tired and boycott. Suspense is an advertisement form with witty and higher aesthetic taste. As a kind of omitting type, suspense advertising leaves audiences with a certain freedom of imagination, to arouse their thinking. Due to the particularity of advertising rhetoric art, suspense advertising strives to make people explore the inner information of advertising subtly through the psychology of amazing and being satisfied after knowing the results.

\section{B. Communication Advantage of Suspense Advertisement}

Modern people have higher aesthetic requirements for advertising, and they refuse plain advertising that has no originality, but admire the amazing and inspiring creative advertising works. The application of suspense skills in advertising makes advertising not so pale and easier for audiences to accept the commercial information conveyed by advertising. Today, suspense skill is very common in advertisement design, and the success of many brand advertising is benefited from the appealing suspense art to a large extent. Suspense advertising not only can transmit the product information to consumer, but also convey the enterprise spirit containing wisdom, confidence and optimism, leaving people room of aftertastes. The application of suspense skills in commercial advertising has obtained more and more attention with rapid development. Now, suspense skills have been used in all kinds of advertising in China, with the unique and novel advertising emerging in an endless stream. The application of suspense skills has been one of the important creative tendencies for modern advertising, leading the trend of advertising.

The reason why we use suspense expression method in advertising creative is that it will give us unexpected results. It 
can create a relaxed and mysterious state, and then place its purpose and intention into audiences' mind subtly. Suspense advertising has created correlation with the expression of product information through unique suspense skills, and by watching advertisements, the curiosity and thirst for knowledge in people's heart will be able to be released. Suspense can not only strengthen the appreciation value of advertising, at the same time, can make the appeal point of advertisement more clear. Using suspense skill and making full use of dramatic conflicts, can reverse the public's qualitative thinking, enabling people's memory of advertisement more durable and clearer through association and imagination. The implicit expression of suspense advertisement has avoided audiences' resentment toward advertisement while enhancing persuasion.

\section{CREATIVE STRATEGIES OF SUSPENSE AdVERTISEMENT}

The creative strategies of suspense skills in advertising are generally divided into using language skillfully, making good use of graphic images and setting story plots wonderfully. These three creative expression forms can not only be used independently, but they can be used in combination to make the suspense advertisement more suspense and more attractive.

\section{A. Use Language Skillfully}

The role of language in advertising is particularly important. It is the soul of advertising and is vital to a successful advertising. The languages of suspense advertising are generally attractive, with sparks of wisdom, and full of wisdom and imagination. The language in suspense advertisement should not only arouse consumers' interest, strengthen the language expressive force of suspense advertising, but also shall improve audiences' attention to the advertisement, extend their memory time of commercial information, so as to ultimately facilitate the consuming behavior. Therefore, the creation of suspense slogan must be made from unique perspectives. The application of suspense in advertising language is usually realized by visual language and auditory language and other aspects. Visual language should has dual function: on the one hand, with the function of information transmission, advertisement creators make the characters and symbols more strong and distinctive, and the visual function with information transmission effect is more specific; on the other hand, it provides the language with psychological function of expressing feelings via vivid character patterns. Auditory language in suspense advertisement generally adopts intelligent statements and takes full advantage of people's curiosity and their psychological needs of desire, to design and create suspense skillfully, arouse the audiences' conjecture, and make people generate keen interest in advertising products. The suspense advertisement language full of wisdom can display the advertisement creator's active thinking and artistic creativity in full, improving the appealing and acceptance of the advertisements, so as to eventually improve the brand awareness and purchasing volume. It is important to note that we shall pay attention to the language habits of this nation in this region while creating suspense using language, to learn cultural taboos. If it is used improperly, then the suspense artistic effect will be reduced and even cause side effects.

\section{B. Make Good Use of Graphics}

Graphic is a kind of visual language, and it primarily creates suspense using the unnatural and intriguing images. Generally, the graphics with strong visual impact and sense of suspense to show final result of the plot, and inspire audiences' strong psychology of expectation and exploration, enabling audiences to imagine the whole process of plot. Because the result has been given out, it is convenient for audiences to trace the source using imagination, thus to complete the plot process. Suspense advertisements can be divided into two kinds from the perspective of form: one is single suspense advertisement, namely to express the information of the whole advertisement using only one image; the other is serial suspense advertisements, namely to complete an advertisement using two or more images, which is like several images made by the key scenes picked up from an television advertisement, and these images can appear on one same page or different pages, and can even appear in different time according to different media and the needs of advertising. This kind of suspense advertisement is generally published in magazines or newspapers and other print media.

\section{Set Story Plots Wonderfully}

The psychological basis for the existence of suspense advertising is people's curiosity and thirst for knowledge. Its basic structure is setting up question, analyzing questions and giving out the answer. The advertising forms of television advertising, broadcasting and micro film advertising and other forms with the feature of timeliness and unique audio-visual advantages are more suitable for using suspense compared with language and image form, to attract audiences via some uncertain story plot, make people to produce doubt, and successfully draw people's attention focus, thus arouse people's curiosity and explore desire to strongly expect the plot progress after suspense. Suspense can be made easily using audio-visual media, and the amazing suspense effect can be generated with short blank, distinctive voice, innovative ideas and special audio visual effect. It is worth noting that the key point of plot suspense advertising is to grasp the opportunity. If the answer is given out to early or too late, we can only get half results, which cannot effectively accumulate the attention of people and convey brand information.

\section{Role of SusPense SKILls IN AdVERTISING}

Advertising is a kind of communication form to convey specific information to specific object at specific time with specific medium to achieve specific purpose. So it can be said that advertising is an art of promotion. Advertising is conducive to establish corporate and product image, guide consumption demand and stimulate the purchase desire. Suspense skills have great psychological effect value in advertising. The same commercial information will have better advertising effect if it is expressed using suspense skills. A good suspense advertisement not only can leave deep impression to people, but more important is that it can bring huge brand image effect to the enterprise. This not only 
contains the factor of product itself, but also contains the psychological value brought by such potential factors as advertising form and expression technique. Suspense advertising makes full use of people's curiosity psychology, setting up questions, making people puzzled at first glance of the advertisement, arousing their curiosity to guess and pay attention to it, creating a suspicion and tension psychological state, to open consumers' positive thinking and lead the audiences to further explore the theme of this advertisement, and then give out the answer in due time to remove the suspense, which belongs to self-answering. Suspense skills have just taken advantage of people's such psychological value to have greater advantages over other ordinary advertising.

From the perspective of advertising psychology, a key factor evaluate advertising works is whether or not it can get audiences' attention, and it applies to print advertising, broadcast advertising and film and television advertising. Suspense skills are commonly used in series suspense advertising. Driving by curiosity, consumers' unconscious attention on the contents of advertisements will be gradually transformed into voluntary attention, to deepen information memory given by the advertisements, and pay attention to and seek clues about advertising information positively. It is the positive effect of suspense advertising doubles advertising creators' favor toward it.

\section{PROSPECT OF SUSPENSE ADVERTISING}

Modern people's daily life is filled with advertisements in the information age. People start to pay attention to brand effect, and their requirements of advertising are improved with their enhanced appreciation ability. They prefer creative advertising forms. Suspense advertising displays its own artistry, culture and uniqueness, holding a position in advertising market with attractive personality, showing its infinite charm on the colorful stage of advertising.

The utility of commercial advertising is inevitable, which leads to consumers' doubts and resistance to advertisements. And suspense advertising has successfully attracted audiences' attention through the way of self-answering. The audiences' bad feelings and alert to advertising are weakened and eliminated, and the distance between goods and consumers is shortened to weaken the direct impression of utilitarianism in advertising. The strengthening of advertising persuasiveness has promoted the formation of people's good attitude toward products and brands, to make people accept the commodity information transmitted by advertisements, to reach tacit understanding of natural transmission, and purchase goods according to the advertisements' persuasion, thus to achieve the "winding" business purpose. Suspense advertising has increasingly attracted audiences' interest and attention, allowing audiences to accept the message conveyed by advertisements with curious mood. The position of suspense advertising in the future is immeasurable, and it will bring more social and economic effect to the merchants.

\section{CONCLUSION}

The forms of advertising creativity are diversified. The wide application of suspense skills in advertisement is in a rising trend, which publicizes product information for the enterprises, but more important is that is can leave the audiences with a profound brand impression, stimulate their desire to buy the product, and bring better economic effect to the enterprise. The application of suspense skills in advertising creative through language, graphics and plots make the advertisement more attractive. Consumers will get psychological shock, focus on advertising and like advertising by watching advertisements, thus to stimulate their purchase desire, which is the final wish of advertising creators and merchants. The exploration of expression forms of suspense skills in creative advertising is conducive for the designers to convey relevant information more accurately and effectively according to the needs of consumers, via using modern suspense design concept and mobilizing various visual information elements. Suspense advertising is in a stage of rapid growth and being focused by people, and only by constantly innovation, can the suspense skills be given play to its fullest.

\section{REFERENCES}

[1] Luo Lin. Suspense Advertising in Print Media [J]. Decoration. 2003(06)

[2] Li Qi. Plane Suspense Advertising under Multimedia Context: Disappear or Be Extended [J]. Youth Journalist. 2013(20).

[3] Cai Zhiguo. Application of Suspense in Television Advertisements [J]. Media Observer. 2009(01).

[4] Gu Qianqian. "Standing in Motion" and "Transform Static to Dynamic"-Analysis of Visual Language in Modern Print Advertisement [J]. Meiyuan. 2012(06). 